\title{
Sustainability of Aquaculture: Applications of Environmental Model
}

\author{
Serap Pulatsu \\ Ankara University, Faculty of Agriculture, \\ Department of Fisheries and Aquaculture Engineering, 06110- Ankara, Turkey \\ E-mail: spulatsu@agri.ankara.edu.tr
}

\begin{abstract}
Aquaculture is characterized by three elements as the species to be cultured, the facility/area where the aquaculture will take place and the environment. The sustainability of aquaculture where the socioeconomic benefits could not be ignored, is based on appropriate management strategies that do not harm the ecosystem. This compilation study emphasized on the following issues in line with sustainable aquaculture: a) The definition and significance of mathematical models were clarified b) The models developed and put into practice for aquaculture systems were presented c) Environmental models were addressed among the models in question. The study aiming at drawing attention to the environmental mathematical models used at aquaculture has three main topics: 1) The modelling of wastes due to nutrients load and/or aquaculture (estimated). 2) The modelling of the carrying capacity of the potential area for aquaculture 3) The modelling-monitoring of the environmental effects of aquaculture. The estimation of the theoretical carrying capacity (before aquaculture) of different receiving environments (sea, bay-gulf, inland waters) where especially cage fish farms operate, is evaluated as a crucial step in terms of sustainability. Following the aquaculture activity, monitoring practices are considered in order to preserve the production level in a way that will not change the basic environmental quality standards (regarding water-sediment-biota). The mathematical models including interactions between the physical, chemical and biological dimensions of aquaculture and the environment are considered as useful tools in terms of the planning and management of production. Within this context, the development and more comprehensive applications of authentic models that may yield reliable results within a short period and that comprise technological approaches will be beneficial in terms of sustainable aquaculture in Turkey.
\end{abstract}

Keywords: Aquaculture, sustainability, model, carrying capacity, environmental monitoring

DOI: $10.7176 /$ JSTR/5-3-01

\section{Sürdürülebilir Su Ürünleri Yetiştiriciliği: Çevresel Model Uygulamaları}

Özet

Su ürünleri yetiştiriciliği; yetiştiriciliği yapılacak tür, yetiştiricilik faaliyetinin yapılacağı tesis/alan ve çevre gibi üç unsurla karakterize edilmektedir. Sosyo-ekonomik yararları yadsınamayacak su ürünleri yetiştiriciliğinin, sürdürülebilir olması, ekosisteme zarar vermeyen uygun yönetim stratejilerine dayanmaktadır. $\mathrm{Bu}$ derleme çalışmasında sürdürülebilir su ürünleri yetiştiriciliği ekseninde; a) Matematiksel modellerin tanımı ve önemi açıklanmış b) Su ürünleri yetiştiricilik sistemleri için geliştirilmiş ve uygulanmış modeller bir araya getirilerek sunulmuş c) Söz konusu modellerden ise çevresel modellere odaklanılmıştır. Su ürünleri yetiştiriciliğinde kullanılan çevresel matematiksel modellere dikkat çekmeyi hedefleyen çalışmanın kapsamını üç ana başlık oluşturmaktadır; 1) Yetiştiricilik kaynaklı besin elementi yükü ve /veya yetiştiricilikten kaynaklanan atıkların modellenmesi (tahmini) 2) Yetiştiricilik yapılan ortamın taşıma kapasitesinin modellenmesi (tahmini) 3) Yetiştiriciliğin çevresel etkilerinin modellenmesi-izlenmesi. Zira özellikle su ürünleri kafes işletmelerinin faaliyet gösterdiği farklı alıcı ortamların (deniz, koy-körfez, iç sular) faaliyet öncesi teorik taşıma kapasitesinin tahmini, sürdürülebilirlik açısından önemli bir basamak olarak değerlendirilmektedir. Yetiştiricilik faaliyeti sonrasında ise temel çevresel kalite standartlarını (su-sediment-biyotaya ilişkin) değiştirmeyecek şekilde üretim seviyesini muhafaza etmek amacıyla izleme uygulamaları esas

1 I $\mathrm{P}$ a g e

www.iiste.org 
alınmaktadır. Yetiştiriciliğin fiziksel, kimyasal ve biyolojik boyutları ile çevre arasındaki etkileşimleri içeren matematiksel modeller, üretimin planlanması ve yönetimi açısından faydalı araçlar olarak değerlendirilmektedir. Bu bağlamda, Türkiye'de de kısa zamanda güvenilir sonuç verebilecek ve aynı zamanda teknolojik yaklaşımları içeren özgün modellerin geliştirilmesi ve daha yaygın uygulamaları, sürdürülebilir su ürünleri yetiştiriciliği açısından yararlı olacaktır.

Anahtar kelimeler: Su ürünleri yetiştiriciliği, sürdürülebilirlik, model, taşıma kapasitesi, çevresel izleme

\section{Giriş}

Su ürünleri yetiştiriciliği, özellikle gelişmekte olan ülkelerde yüksek kaliteli proteinin en uygun ve ucuz kaynağı olarak değerlendirilmektedir. Dünya nüfusunun 2030 yılında 8,6 milyara ulaşmas öngörülmekte, beslenme ekseninde protein ihtiyacı açığını karşılayabilecek kaynakların başında ise su ürünleri gelmektedir. Türkiye'deki toplam su ürünleri üretimi 2017 verilerine göre 630.820 ton olup, üretimin 354.318 tonu avcılıktan, 276.502 tonu da yetiştiricilikten sağlanmaktadır. Aşırı avlanma ve kirlilik gibi faktörler nedeniyle avcılık üretimimiz sınırlanırken, su ürünleri yetiştiriciliği ivme kazanmaya devam etmektedir. Bu kapsamda; ülkemizde 1.881 adedi iç sularda ve 427 adedi denizlerimizde olmak üzere toplam 487.859 ton kapasiteli 2.308 adet balık işletmesi bulunmaktadır (BSGM, 2018). Su ürünleri yetiştiricilik sistemleri öncelikle yeterli miktarda ve iyi kalitede suya ihtiyaç duyduğundan, sürdürülebilir su ürünleri yetiştiriciliği-çevre etkileşiminin çerçevesini, su kaynaklarının kirlenmesine yol açmadan ve ekosisteme zarar vermeden başarmak çizmektedir.

Entansif su ürünleri yetiştiriciliğinin amacı, birim alandan alınan biyomas miktarını maksimize ederek kazanç artışı sağlamaksa da bu amaçla yapılan aşırı stoklamaya paralel gelişen olumsuz ortam koşullarının, işletmenin sürdürülebilirliğini ve rantabilitesini olumsuz etkilemesi kaçınılmazdır. Yetiştiriciliğin gelişimi açısından işletme karlılı̆ı ve sürdürülebilir işletme faaliyetleri arasında kabul edilebilir bir denge olması gerektiğinden yetiştiriciliğin yönetimi, su kalitesinin yönetimi ile eşdeş olup, başarılı bir üretimin de ön koşuludur. Bu bağlamda, ekosistem proses ve interaksiyonları hakkında yeterli bilgi birikimi, su kalitesinin yönetiminde ve yoğun su ürünleri yetiştiricilik sistemlerinin çevresel olumsuz etkilerini azaltmada önemli bir unsurdur.

Entansif su ürünleri yetiştiriciliği, yetiştiricilik yapılan alanın çevresel koşullarını da önemli ölçüde etkilemekte; yetiştiricilik kaynaklı kirlenmenin boyutları stok yoğunluğu, besleme yöntemi, su kalitesi ve işletmecilik gibi faktörler ile kültüre alınan türler ve uygulanan yetiştiricilik tekniğine göre değişmektedir. Yetiştiriciliğin su ortamı üzerindeki etkileri; alıcı sedimentlerin organik zenginleşmesi, su kalitesi, besin maddesi bakımından zenginleşme ve alg patlamaları, yabani balık stokları, yabani hayat, nadir türler, hastalık, takdim / transfer ile ekolojik / biyolojik etkileşimler ve besin ağı etkileşimleri, hidrolojik düzen, drenaj, fiziki yapıların rahatsız edilmesi ile habitatın bozulması, atık boşaltımı, kimyasal maddelerin kontrolsüz kullanılması şeklinde özetlenebilir (Pulatsü et al. 2014). Bu bağlamda, su ürünleri yetiştiriciliğinin sağladığı sosyo-ekonomik yararlar gözardı edilmeksizin akılcı planlama ve uygun yönetim stratejileri ile çevrenin korunması ve yetiştiriciliğin çevre üzerindeki olası etkilerinin en aza indirgenmesi hedeflenmektedir (Pulatsü \& Kaya 2016a).

Su ürünleri yetiştiriciliğinde matematiksel modellerin kullanımı; a) Balığın yetiştirildiği ortamın ve yetiştiricilik kaynaklı atıkların yönetimi için sistemdeki kompleks interaksiyonların değerlendirilmesini kolaylaştırmak ve sistem dinamiği proseslerinin anlaşılmasına yardımcı olmak b) Yetiştiricilik sisteminin anlık durumunu ve çevresel etkisini tahmin etmek gibi iki temel amaca hizmet etmektedir.

$\mathrm{Su}$ ürünleri yetiştiricilik araştırmalarında modelleme kantitatif ve kesin metotların kullanımını hızlandıran en önemli adımdır. Kafeslerde su ürünleri yetiştiriciliği açısından çevresel modelleme, alıcı ortamın (deniz, koy-körfez, iç sular) kafes işletmeleri faaliyete geçmeden önceki teorik taşıma kapasitesini tahmin etmek, izleme ise dikkate alınan (geçerli) kalite standartlarını değiştirmeyecek şekilde çevresel etkiyi korumak amacıyla kullanılmaktadır.

$\mathrm{Bu}$ derleme çalışmasında, su ürünleri yetiştiriciliğine ilişkin farklı tipteki modeller özetlenerek model uygulamalarının önemi vurgulanmaya çalşsılmış, bu modellerden özellikle çevresel modellere odaklanılmıştır. Ayrıca Türkiye'de konu ile ilgili çalışmalara ve alıcı ortamlardaki su ürünleri işletmelerinin çevresel etkilerini belirleme - izlemede esas alınan yasal düzenlemelere de değinilmiştir.

\subsection{Su Ürünleri Yetiştiriciliği - Matematiksel Modeller}

Karmaşık yapıya sahip sistemlerin-varlıkların-süreçlerin (proseslerin), cisimlerin, olayların incelenip araştırılmasını ve anlaşılmasını kolaylaştırmak için gerçeğe uygun bir takım (fiziksel, kimyasal, biyolojik, jeolojik vb) kanun ve kurallara dayanan varsayımlarla basitleştirilmiş haline "model" denir. 
Matematiksel bir model, en genel anlamıla herhangi bir sistemin veya bir sürecin ana özelliklerini matematiksel terimlerle ve simgelerle ifade eden bir eşitlik veya formül olarak tanımlanabilir. Modeller; a) Kavramsal ve matematik modeller b) Ampirik ve teorik modeller c) Mekanistik-teorik modeller d) Deterministik ve stokastik modeller e) Statik ve dinamik modeller f) Kesintili/ayrı ve sürekli modeller şeklinde sınıflandırılmaktadır (Roy 2006; Mikailsoy 2019).

Anyadike et al., (2016) tarafindan su ürünleri yetiştiricilik sistemlerine ilişkin modeller aşağıda sunulduğu üzere sekiz grupta sınıflandırılmıștır:

- Biyolojik modeller: Yetiştiriciliği yapılan balıkların büyüme, yaşama oranı, üreme, beslenme, solunum ve boşaltım gibi reaksiyonları ile yetiştirildikleri ortamın modellenmesine yöneliktir.

- Mühendislik modelleri: Dizayn, yönetim ve balıkların yetiştirildikleri ortamın kontrolüne yönelik modeller olup, balıklara özgü hangi tip yetiştiricilik ortamının gerektiğini veya uygun olduğunu belirlemek için kullanılan modellerdir.

- Biyoekonomik veya ekonomik modeller: Su ürünleri yetiştiricilik işletmelerinin ekonomik fizibilitesi ile ilgili maliyet tahmini, üretim gelirleri ve yetiştiricilik ortamını muhafaza etmeye yönelik bu modeller, biyolojik ve mühendislik modelleri ile bağlantılı olup, ekonomik analizi esas alarak üretim fonksiyonunu tanımlamak için kullanılmaktadır.

- Büyüme modelleri: Balık büyümesi, yem alımı, hayvansal doku oluşumu ile metabolitlerin eksraksiyonunu içine alan fizyolojik ve davranışsal bir dizi kompleks proseslerin sonucudur. Büyüme modelleri, maksimum büyümeyi etkileyebilen su sıcaklığı, oksijen ve iyonize olmamış amonyak konsantrasyonu, besin bulunabilirliği, tuzluluk, fotoperiyot vb gibi çevresel (dış) ve genotipi de kapsayan iç faktörlerden birkaçı veya tümünün birleşik etkisine dayanmaktadır.

Çizelge 1'de balık yetiştiriciliğinde uygulanan büyüme tahmin modelleri sunulmuştur.

Çizelge 1. Balık yetiştiriciliğinde uygulanan büyüme tahmin modelleri (Cho 1992; Shearer 1995; Bueno et al. 2017)

\begin{tabular}{|c|c|}
\hline Büyüme tahmin modelleri & $\begin{array}{l}\text { Büyüme modelleri ve balık enerji } \\
\text { gereksinimleri arasındaki enterasyon }\end{array}$ \\
\hline $\begin{array}{l}\mathrm{GR}=\left(\mathrm{W}_{\mathrm{t}}-\mathrm{W}_{\mathrm{i}}\right) / \mathrm{W}_{\mathrm{i}} \\
\mathrm{GRR}=\left(\mathrm{W}_{\mathrm{t}}-\mathrm{W}_{\mathrm{i}}\right) / \mathrm{W}_{\mathrm{i}} \times \Delta \mathrm{t} \\
\mathrm{GR} \text { : Nisbi büyüme; GRR: Oransal ağırlık artış1; } \mathrm{W}_{\mathrm{t}} \text { : } \\
\text { Deneme sonu ort. ağ.; } \mathrm{W}_{\mathrm{i}} \text { : Deneme baş1 ort. ağ.; } \Delta \mathrm{t} \text { : İki } \\
\text { tartım arası süre }\end{array}$ & $\begin{array}{l}\mathrm{C}=\mathrm{ME}+\mathrm{GR}+\mathrm{E} \\
\mathrm{C}: \text { Sindirilebilir enerji; ME: Metabolize } \\
\text { edilebilir enerji; GR: Nisbi büyüme; E: } \\
\text { İçsel boşaltım }\end{array}$ \\
\hline $\begin{array}{l}\mathrm{SGR}=\left[\left(\ln _{\mathrm{f}}-\ln \mathrm{P}_{\mathrm{i}}\right) / \mathrm{d}\right] \times 100 \\
\mathrm{SGR}: \text { Spesifik büyüme oranı; } \mathrm{P}_{\mathrm{f}}: \text { Deneme sonu ağ.; } \mathrm{P}_{\mathrm{i}} \text { : } \\
\text { Deneme başı ağ.; } \ln \text { : e tabanına göre log.; d: Deneme süresi } \\
\text { (gün) }\end{array}$ & $\begin{array}{l}\mathrm{C}=[(\mathrm{G}+\mathrm{E}-\mathrm{U}) / \mathrm{A}] / \mathrm{F} \\
\mathrm{C} \text { Balıkların besinsel esansiyel } \\
\text { elementlere günlük gereksinimi; G: Yeni } \\
\text { doku sentezi için olan gereksinim; E: İçsel } \\
\text { kayıplar; U: Elementin sudan alınan } \\
\text { miktarı; A: Elementin biyoyararlılığı; F: } \\
\text { Yem alım miktarı }\end{array}$ \\
\hline $\begin{array}{l}\text { DGC }=\left[\left(\mathrm{P}_{\mathrm{f}} 1 / 3-\mathrm{P}_{\mathrm{i}} 1 / 3\right) / \mathrm{d}\right] \times 100 \\
\text { DGC: Günlük büyüme katsayıs1; } \mathrm{P}_{\mathrm{f}} \text { : Deneme sonu ağ.; } \mathrm{P}_{\mathrm{i}} \text { : } \\
\text { Deneme baş1 ağ.; d: Deneme süresi (gün) } \\
\text { 1/3: üssel büyüme oran1 }\end{array}$ & $\begin{array}{l}\mathrm{P}_{\mathrm{d}}=\mathrm{ME}-\mathrm{R} \\
\mathrm{P}_{\mathrm{d}}: \text { Üretim; R: Solunum } \\
\mathrm{ME} \text { - R: Alıkonulan-tutulan enerji }\end{array}$ \\
\hline \multirow{2}{*}{$\begin{array}{l}\text { LGC }=\left(\mathrm{P}_{\mathrm{f}}-\mathrm{P}_{\mathrm{i}}\right) / \mathrm{d} \\
\text { LGC: Linear büyüme katsayısı; } \mathrm{P}_{\mathrm{f}} \text { : Deneme sonu ağ.; } \mathrm{P}_{\mathrm{i}} \text { : } \\
\text { Deneme baş1 ağ.; d: Deneme süresi (gün) }\end{array}$} & Biyoenerjitik faktöriyel model \\
\hline & \multirow{2}{*}{$\begin{array}{l}\text { Esas1 sicaklı̆ga bağlı yem tüketimi ve } \\
\text { büyüme verilerine dayanan } \\
\text { FishBioenergetics, version } 3.0 \text { bilgisayar } \\
\text { yazılım programı }\end{array}$} \\
\hline $\begin{array}{l}\text { TGC }=\left\{\left[\mathrm{P}_{\mathrm{f}}(1-\mathrm{b})-\mathrm{P}_{\mathrm{i}}(1-\mathrm{b})\right] / \Sigma \mathrm{t} \times \mathrm{d}\right\} \times 100 \\
\text { TGC: Termal büyüme katsayısı; } \mathrm{P}_{\mathrm{f}}: \text { Deneme sonu ă̆.; } \mathrm{P}_{\mathrm{i}}: \\
\text { Deneme başı ağ.; } \mathrm{d} \text { : Deneme süresi (gün); t: Sicaklık }{ }^{\circ} \mathrm{C} ;(1 \\
\text { - b) vücut ağırlığının üssü }\end{array}$ & \\
\hline
\end{tabular}


- Havuz ekosistem modelleri: Havuz ortamına ilişkin pekçok bileşen ve prosesi kapsayan modellerdir. $\mathrm{Bu}$ bileşenler; biyotik bileşenler (yetiştiriciliği yapılacak organizmalar, fitoplankton, zooplankton, bentik organizmalar, bakteri-detritus kompleksi), abiyotik bileşenler ( $\mathrm{pH}$, alkalinite, karbondioksit, sıcaklık, çözünmüş oksijen, amonyak-amonyum, nitrit, nitrat, fosfor, organik madde gibi su kalite özellikleri yanında toprak tipi ile rüzgar, buharlaşma, yağış gibi iklimsel faktörler) ve havzadan gelen sediment, besin elementleri ve gübreler gibi antropojenik aktivitelerden oluşmaktadır.

- UÜretim modelleri: Yetiştiriciliği yapılan organizmaların yaşama oranı ve büyümesine dayalı modeller olup, üretim toplam ağırlık veya balık biyoması olarak ifade edilmektedir. Hasat edilen balıkların büyüklük dağılımı, pazar ağırlığına ulaşan balıkların sayısını belirlemek açısından önem taşımaktadır.

- Yaşam oranı modelleri: Pekçok yaşama oranı modeli, geçmiş deneyimlere dayanarak yetiştiricilik periyodunun sonunda yaşama oranı için beklenen düzeyi tahmin etmektedir. Doğrusal veya doğrusal olmayan eşitlikler, yetiştiricilik boyunca yaşama oranını tahmin etmek için uygundur.

- Çevresel modeller: Kompleks çevresel durumları basitleştirmek için bilgi ve deneyime dayanan simülasyonlardır. Son yıllarda bilimsel anlamda da popüleritesi ve önemi artan bu modeller aşağıda kapsamlı bir şekilde ele alınmıştır.

\section{2 Çevresel matematiksel modeller}

Su ürünleri yetiştiriciliğinde her bir türün habitat, çevre ve beslenme şekli farklılık gösterdiği gibi türlerin üreme, fizyolojik ve patolojik özellikleri de değişim göstermektedir. Benzer şekilde yetiştiricilik faaliyetinin yapılacağ 1 tesisler tank, havuz, tatlı-tuzlu veya acı sudan okyanusa kadar değişmekte ve yetiştiricilik tipine göre (monokültür, polikültür) farklılık göstermektedir. Bu bağlamda su ürünleri yetiştiriciliği; yetiştiriciliği yapılacak tür, yetiştiricilik faaliyetinin yapılacağı tesis/alan ve çevre gibi üç unsurun karışımıdır. Su ürünleri yetiştiriciliğinde kullanılan çevresel modeller, üç ana başlık altında toplanabilir; a) Yetiştiricilik kaynaklı besin elementi yükü ve /veya yetiştiricilikten kaynaklanan atıkların modellenmesi (tahmini) b) Yetiştiricilik yapılan ortamın taşıma kapasitesinin modellenmesi (tahmini) c) Yetiştiriciliğin çevresel etkilerinin modellenmesi-izlenmesi.

\section{a) Yetiștiricilik kaynaklı besin elementi yükü / atıkların tahminine ilișkin modeller}

Su ürünleri yetiştiricilik faaliyetlerinin sürdürülebilirliği ve çevresel etkisinin belirlenmesine ilişkin ilk adım, üretimle (gerçek veya öngörülen) ilgili atık miktarının objektif olarak tahmin edilmesidir. Bu bağlamda, karada kurulu işletmeler ile ağ kafes işletmelerine ilişkin besin elementi yükünü tahmin eden basit besin elementi kütle-denge modelleri, işletme etkilerini izlemede ve atıkların indirgenmesi için hedef belirlemede etkin bir araçtır.

Besin elementi - bütçe dengesi veya kütle denge modeli; a) Yemden gelen besin elementi miktarı (girdisi) b) Yetiştiriciliği yapılan balıkta besin elementinin tutulma oranı c) Üretim düzeyine bağlı olarak ortama bırakılan besin elementi miktarı arasındaki ilişkileri belirlemek için kullanılır. Başka bir deyişle, balık işletmelerinden kaynaklanan kirletici miktarı veya besin elementi yükü; yemleme oranları, yem değerlendirme oranları, yemin azot ve fosfor içeriği veya yemin sindirilebilirliğine ilişkin veriler kullanılarak tahmin edilebilir (Alvarado 1997). Balık yetiştiricilik sistemlerine özgü başlıca potansiyel kirleticiler olan azot ve fosfor fraksiyonları, çözünmüş veya partiküler halde alıcı ortama girmekte olup, azotlu-fosforlu atıkların miktarı yemin protein düzeyine ve sindirilebilirliğine bağlıdır. Çizelge 2'de farklı balık türlerine ait azot ve fosfor kütle-denge sonuçları sunulmuştur (Dominguez et al. 1997). 
Çizelge 2. Farklı balık türlerinin yetiştiriciliğinde azot ve fosfor kütle dengesine ait veriler (Dominguez et al. 1997)

\begin{tabular}{|c|c|c|c|c|}
\hline Balık türü & $\begin{array}{l}\text { Yetiştirme } \\
\text { şekli }\end{array}$ & $\begin{array}{l}\text { Yemdeki besin } \\
\text { elementi }(\%)\end{array}$ & $\begin{array}{l}\text { Balikta } \\
\text { tutulan besin } \\
\text { elementi }(\%)\end{array}$ & $\begin{array}{l}\text { Besin } \\
\text { elementi yükü }\end{array}$ \\
\hline $\begin{array}{l}\text { Kanal yayını (Ictalurus } \\
\text { punctatus) }\end{array}$ & Havuz & $\begin{array}{l}\% 5 \mathrm{~N} \\
\% 1 \mathrm{P}\end{array}$ & $\begin{array}{l}\% 28 \mathrm{~N} \\
\% 29 \mathrm{P}\end{array}$ & $\begin{array}{l}\% 72 \mathrm{~N} \\
\% 71 \mathrm{P}\end{array}$ \\
\hline $\begin{array}{l}\text { Gökkuşağ1 alabalığ } 1 \\
\text { (Oncorhynchus mykiss) }\end{array}$ & Kafes & $\begin{array}{l}\% 6-9 \mathrm{~N} \\
\% 1.1-1.6 \mathrm{P}\end{array}$ & $\begin{array}{l}\% 27-28 \mathrm{~N} \\
\% 17-19 \mathrm{P}\end{array}$ & $\begin{array}{l}\% 67-71 \mathrm{~N} \\
\% 78-82 \mathrm{P}\end{array}$ \\
\hline $\begin{array}{l}\text { Gökkuşağ1 alabalığ1 } \\
\text { (Oncorhynchus mykiss) }\end{array}$ & Kafes & - & $\begin{array}{l}\% 26 \mathrm{~N} \\
\% 18 \mathrm{P}\end{array}$ & $\begin{array}{l}\% 74 \mathrm{~N} \\
\% 87 \mathrm{P}\end{array}$ \\
\hline $\begin{array}{l}\text { Gökkuşağ1 alabalığ } 1 \\
\text { (Oncorhynchus mykiss) }\end{array}$ & Kafes & - & $\begin{array}{l}\% 27.7 \mathrm{~N} \\
\% 29.8 \mathrm{P}\end{array}$ & $\begin{array}{l}\% 72.3 \mathrm{~N} \\
\% 70.2 \mathrm{P}\end{array}$ \\
\hline Salmon (Salmo salar) & Kafes & - & $\begin{array}{l}\% 25 \mathrm{~N} \\
\% 23 \mathrm{P}\end{array}$ & $\begin{array}{l}\% 75 \mathrm{~N} \\
\% 77 \mathrm{P}\end{array}$ \\
\hline Çipura (Sparus aurata) & Havuz & $\begin{array}{l}\% 6 \mathrm{~N} \\
\% 1.2 \mathrm{P}\end{array}$ & $\begin{array}{l}\% 26 \mathrm{~N} \\
\% 21 \mathrm{P}\end{array}$ & $\begin{array}{l}\% 74 \mathrm{~N} \\
\% 79 \mathrm{P}\end{array}$ \\
\hline Çipura (Sparus aurata) & Kafes & $\begin{array}{l}\% 7.5 \mathrm{~N} \\
\% 1 \mathrm{P}\end{array}$ & $\begin{array}{l}\% 22.2 \mathrm{~N} \\
\% 27.8 \mathrm{P}\end{array}$ & $\begin{array}{l}\% 77.8 \mathrm{~N} \\
\% 72.2 \mathrm{P}\end{array}$ \\
\hline
\end{tabular}

Alıcı ortamlarda fosfor, su kalitesini doğrudan etkileyen organik fosfor (organik-P) ve fosfattan $\left(\mathrm{PO}_{4}\right)$ oluşan çözünür form ile tabana çöken veya biriken partiküler formdan oluşmaktadır. Balıklarca eksrakte edilen fosfor sucul ortamın zenginleşmesinde ve alg büyümesinde doğrudan etkiye sahiptir. Yemde fosforun sindirilmeyen fraksiyonu dışkıyla, balığın ihtiyacından fazla olan sindirilebilen kısmı ise ortofosfat formunda üre ile atılmaktadır. Üredeki inorganik fosfor formu bitkiler tarafindan kullanıma uygun iken, primer verimliliği teşvik eden ve alg tarafindan kullanılabilen fosfor formu çözünmüş olmalıdır. Balığın dışkısındaki fitat-P ve fosforun diğer organik formları, sucul ortamdaki bakteriler ve diğer organizmalarca çözündürülür (Canale et al. 2016). Yetiştiricilikten kaynaklanan azotlu atıkları etkileyen temel faktörler ise balıklarda aminoasitlerin katabolizması ve depolanmasıdır.

Bureau \& Hua (2010) tarafindan bildirilen yetiştiricilikten kaynaklanan atıkların tahminine ilişkin formüller Eşitlik 1-4'de sunulmuş̧ur:

Katı atık materyal $=$ Tüketilen yem $\mathrm{x}(1-\mathrm{SK})$

Kat 1 fosfor atığ $\breve{1}_{1}$ Tüketilen yem x Yemin fosfor içeriği $\left(1-\mathrm{SK}_{\text {fosfor }}\right)+$ Tüketilmeyen yem $\mathrm{x}$ Yemin fosfor içeriği

Katı azot atı̆g $1=$ Tüketilen yem x Yemin azot içeriği $\left(1-S_{\text {ham protein }}\right)+$ Tüketilmeyen yem x Yemin azot içeriği

SK: Sindirilebilirlik katsayısı

Toplam atık = Katı atık materyal + Çözünmüş atık materyal + Yem kayıpları atığı

Bueno et al. (2017) tarafindan teorik yem miktarı ve gereksiniminin ise 1sı kayıplarını da kapsayan besinsel enerji dengesine dayanarak hesaplanabileceği, çözünmüş besin elementlerinin de aşağıdaki formüllere (Eşitlik 5-6) göre tahmin edilebileceği bildirilmiştir:

Çözünmüş fosforlu atıklar = Sindirilebilir fosfor alımı - Karkasta tutulan fosfor

Çözünmüş azotlu atıklar = Sindirilebilir azot alımı - Karkasta tutulan azot

Hidrodinamik modelle bütünleşmiş faktöriyel biyoenerjitik modellerin, atık yükünün belirlenmesinde ve rezervuarlarda balık üretimi için taşıma kapasitesini hesaplamada kullanılacak değerlerin tahminine yardımcı olacağı, bu yaklaşımın ise göl ve rezervuarlardaki su ürünleri yetiştiricilik işletmelerinin yönetimine ve izlenmesine olanak sağlayacağı belirtilmiştir. Böylelikle sürdürülebilir su ürünleri yetiştiriciliğini desteklemek için daha düşük çevresel etkiye sahip yem kullanımı gibi yönetim teknikleri

5 | P a g e www.iiste.org 
konusunda yetiştiricileri teşvik etmenin de mümkün olacağı bildirilmiştir (Bueno et al. 2017).

b) Alıcı ortamlarda taşıma kapasitesinin tahminine ilişkin modeller

Alıcı ortamlarda kurulu kafes işletmelerinin sürdürülebilirliğgi, bulunduğu alıcı ortam ekosisteminin sürdürülebilirliği ile doğrudan ilgilidir. "Ekosistem esaslı su ürünleri yetiştiriciliği” yaklaşımı, geniş bir ekosistem içerisinde su ürünleri yetiştiriciliğinin entegrasyonu olarak tanımlanmakta ve üç temel prensibe dayanmaktadır;

- $\quad$ Su ürünleri yetiştiriciliğinin gelişimi ve yönetimi, tüm ekosistem işlevlerini dikkate almalı ve bu sistemleri tehdit etmemelidir,

- $\quad$ Su ürünleri yetiştiriciliği, halkın refahı yönünde iyileştirici ve ilgili tüm paydaşlar için eşitlikçi bir yaklaşım sergilemelidir,

- Su ürünleri yetiştiriciliği kapsamındaki tüm diğer sektörler, politikalar ve hedefler geliştirilmelidir (Ross et al. 2013).

Sürdürülebilir su ürünleri yetiştiriciliğinde anahtar unsur; ekosistem yapısında (biyoçeşitlilik) ve ekosistemin işlevlerinde zarara yol açabilecek şekilde besin elementi veya diğer atık madde deşarjının boyutu olduğundan çevresel özümleme kapasitesinin belirlenmesi önem taşımaktadır. Çevresel kapasitenin tahmin edilebilmesi ise su ürünleri yetiştiriciliği konusunda stratejik tedbirlerin alınmasına olanak sağlamaktadır.

Taşıma kapasitesi, -ekosistem esaslı su ürünleri yetiştiriciliğinin- bütünleyici bir parçası olduğundan çevresel sınırlayıcılar ile sosyal uygunluğa dayanan su ürünleri üretiminin üst limitlerini tayin etmeye yardımcı olmaktadır. Temel prensip; uygun kaynak kullanım seviyesini tespit ederek ekosistemin işlevlerinde ve sosyal yapıda kabul edilemez değişime yol açmaksızın sürdürülebilir uzun-dönemli doğal çevre temin etmektir. McKindsey et al. (2006) tarafından, çift kabuklu su ürünleri yetiştiriciliği için dört farklı taşıma kapasitesi tipi tanımlanmıştır (Çizelge 3). Söz konusu tanımlamalar yetiştiriciliği yapılan diğer su ürünleri için de geçerli gözükmektedir.

Çizelge 3. Su ürünleri yetiştiriciliği sistemlerine ilişkin farklı taşıma kapasitesi tipleri (McKindsey et al. 2006)

\begin{tabular}{|c|c|c|}
\hline Modeller & Taşıma kapasitesi tipi & İndikatörler \\
\hline GIS & $\begin{array}{l}\text { Fiziksel: Alıcı ortam için fiziksel } \\
\text { olarak uygun maksimum kafes } \\
\text { sayıs }\end{array}$ & $\begin{array}{l}\text { Su kalitesi, hidrografi, } \\
\text { hidrodinamikler }\end{array}$ \\
\hline $\begin{array}{l}\text { POND } \\
\text { FARM } \\
\text { FAO MODELİ }\end{array}$ & $\begin{array}{l}\text { Üretime dayalı: Hasatın } \\
\text { maksimum olduğu çift kabuklu } \\
\text { stok yoğunluğu }\end{array}$ & $\begin{array}{l}\text { Üretim yoğunluğu, pazar } \\
\text { değeri, ekonomik indikatörler }\end{array}$ \\
\hline $\begin{array}{l}\text { DEPOMOD } \\
\text { MOM } \\
\text { CADS_TOOL } \\
\text { AquaModel }\end{array}$ & $\begin{array}{l}\text { Ekolojik: Ekosistem işlevlerinde } \\
\text { (fonksiyonlarında) kabul- } \\
\text { edilemez ekolojik etkilere yol } \\
\text { açmayacak stoklama veya } \\
\text { işletme yoğunluğu }\end{array}$ & $\begin{array}{l}\text { Atık yayılımı, habitat hasarı, } \\
\text { biyoçeşitlilik ve indikatör türler, } \\
\text { çözünmüş besin elementleri, } \\
\text { ötrofikasyon, bentik hipoksia }\end{array}$ \\
\hline Alg1lar (Kantitatif olmayan) & $\begin{array}{l}\text { Sosyal: Alıcı ortamın sosyal } \\
\text { açıdan kullanımlarını da } \\
\text { etkilemeyecek düzeydeki } \\
\text { maksimum üretim miktarı }\end{array}$ & $\begin{array}{l}\text { Alan çakışması, istihdam ve } \\
\text { hane halk1 geliri, geçim } \\
\text { durumu, rekreasyon, geleneksel } \\
\text { balıkç1lık }\end{array}$ \\
\hline
\end{tabular}

Denizel ekosistemler için taşıma kapasitesi, yetiştiriciliği yapılan balık stoğunun yoğunluğunu ifade etmektedir. Buna ilişkin formül Eşitlik 7'de sunulmuştur:
Üretim kapasitesi $=[150+80 *($ Balık çiftliğinin alanı-1) $] *$ kıyıdan uzaklık katsayısı * derinlik katsayıs $* \mathrm{~F}$

$\mathrm{F}=\mathrm{M} /(\mathrm{G} 1+\mathrm{G} 2) * \mathrm{M} /(\mathrm{L} 1+\mathrm{L} 2)$

$\mathrm{M}=$ Denize doğru körfezin en dar açıklığ

6 I P a g e

www.iiste.org 
$\mathrm{G} 1+\mathrm{G} 2=$ Körfezin temel topoğrafik eksenlerinin toplam1

L1+L2= Körfezin açıklığını belirleyen eksenin (M) iki noktasından balık çiftliğinin merkezine uzaklık

Kapalı sistemlerde $\mathrm{F}$ değeri 0.1 'den küçüktür $(\mathrm{F}<0.1)$. Ağız açıklığı geniş olan koy ve körfezlerde bu değer 0.1-0.67 arasındadır $(0.1<\mathrm{F}<0.67)$. Ağız açıklı̆ğının çok geniş olduğu durumlarda ise bu değer 0.67 'den yüksek $(0.67<\mathrm{F}<1)$ bulunmuştur. İşletme körfezin içindeki bir koyda yer alıyorsa ise $\mathrm{F}$ değeri, $\mathrm{F}=\mathrm{F} 1 * \mathrm{~F} 2$ şeklinde hesaplanır. $\mathrm{F} 1$, koy içindeki işletme için hesaplanırken $\mathrm{F} 2$, koy hariç tutulduğunda körfez için hesaplanan değerdir. Yukarıdaki formülde F katsayısı açık denizler için: 0.67 olarak alınmalıdır (ÇSB 2019).

İskoçya'da denizel kafes işletmelerinin besin elementi girişi ve dip tabakası üzerindeki etkilerine ilişkin kullanılan modellerden biri olan basit kutu (loch) modeli (SEPA 2014) ise, sistemde besin elementlerinin önceki verilere göre artışının tahminine dayanmakta ve bu amaçla aşağıda sunulan basit matematiksel eşitlik (8) kullanılmaktadır:

$\mathrm{ECE}=\mathrm{S} . \mathrm{M} / \mathrm{Q}$

ECE: Denge konsantrasyon artışı $\left(\mathrm{kg} \mathrm{m}^{-3}\right)$

S: Koy-körfeze deşarj edilen azot miktarı ( $\mathrm{kg}_{\text {ton }}$ üretim $\left.{ }^{-1} \mathrm{yl}^{-1}\right)$ (Stoklanan balık türüne göre değişken)

M: Koy-körfezdeki tüm işletmelere ilişkin izin verilebilir toplam maksimum biyomas miktarı (ton)

Q: Koy-körfezin hidrografik özelliklerinden hesaplanmış seyrelme (akış) hızı $\left(\mathrm{m}^{3} \mathrm{yll}^{-1}\right)$

Çizelge 4'de farklı su ürünleri yetiştiricilik sistemleri için geliştirilmiş ve geniş çapta uygulanmış çevresel modelleri de kapsayan matematiksel modeller mümkün olduğunca bir araya getirilerek kronolojik olarak sunulmuştur. Ancak çizelgede yer almayan kıyısal alanlara özgü geliştirilmiş (GESAMP 1991) ve denizel ekosistemlerde kurulu su ürünleri işletmelerinin çevresel etkilerine ilişkin lokal çaplı kullanılan farklı modeller de (ECO Labmodule, DHI Waterand Environment, "VariáveisqueInteragem de ModoSeminquantitativo"(Visq), Structural Thinking Experimental Learning Laboratory with Animation (Stella), Qualres, Ecopath Modeling, "PegadaEcológica", Delph 3D, 3D Water Modeling System (Mohid)) bulunmakta ve bu modeller sucul ortamın dinamik değişkenlerinin simülasyonuna dayanmaktadır.

Fosfor artısıı ve alg büyümesi arasındaki doğrudan ilişkiye dayanan matematiksel modellerden fosfor bütçe modelinin, derin ve sığ göllerde kullanıma uygun olduğu ve içsularda kafeslerde entansif yetiştiricilik yapılacak alıcı ortamların taşıma kapasitesinin tahmininde kullanılabileceği belirtilmiştir (Dillon \& Rigler, 1974). Fosfor bütçe modelinde; gölün morfometrik ve hidrolojik özellikleri ile yetiștiricilikte kullanılan yemin fosfor içeriği ve sindirilebilirliği esas alınmaktadır. Söz konusu model, tüm dünyada olduğu gibi Türkiye'de de farklı ekosistemlerde en çok kullanılan çevresel model olarak karşımıza çıkmaktadır (Verep 2002; Pulatsü 2003; Büyükcapar \& Alp 2006; Aytekin 2007; Aşır \& Pulatsü 2008; Buhan et al. 2010; Polat \& Özmen 2011; Çevlik \& Elibol 2009; Çevlik 2013; Bulut \& Akçimen 2015, Demir et al. 2015). Bunların dışında kafeslerde yetiștiricilikten kaynaklanan azot-fosfor yükünün tahminine ilişkin ve yetiştiriciliğin çevresel etkilerini tahmin etmeye yarayan MOM (Modelling-Ongrowingfishfarms-Monitoring), CADS_TOOL (Cage Aquaculture Decision Support Tool) gibi modeller ile oksijen bütçesini esas alan Tookwinas (2004) Modeli'nin uygulandığ 1 farklı çalışmalar da mevcuttur (Özdal \& Pulatsü 2012; Pulatsü \& Kaya 2016b; Kaya \& Pulatsü 2017). 
Çizelge 4. Su ürünleri yetiştiriciliğinde kullanılan matematiksel modeller

\begin{tabular}{|c|c|c|}
\hline Model & Bilgi & Kaynak \\
\hline Dillon-Rigler & $\begin{array}{l}\text { Çok farklı ve sayıdaki ülkede tatlı su ekosistemlerinde kafeslerde yetiştiriciliği } \\
\text { yapılan tatlısu balıkları için fosforu esas alan modeldir. }\end{array}$ & \begin{tabular}{|c|c|} 
Dillon \& \\
Rigler (1974) \\
\end{tabular} \\
\hline $\begin{array}{l}\text { APEM (Aquaculture Pond } \\
\text { Ecosystem Management) }\end{array}$ & $\begin{array}{l}\text { Farklı tip havuz sistemlerine de uygulanabilen basit, çevre ile dost yetiştiricilik için } \\
\text { geliştirilmiş ve havuzların çevresel ekosistem dinamiklerini içeren modeldir. } \\
\text { STELLA paket programı kullanılır. }\end{array}$ & $\begin{array}{c}\text { Culberson \& } \\
\text { Piedrahita } \\
(1996)\end{array}$ \\
\hline $\begin{array}{l}\text { FIS-C (Fish Simulation } \\
\text { Culture Model) }\end{array}$ & $\begin{array}{l}\text { Su ürünleri yetiştiriciliğinden kaynaklanan atık yüküne dayanan biyoenerji-temelli } \\
\text { bir model olup, hızlı, kısa ve uzun dönemli tahminler yapmaya uygundur. }\end{array}$ & $\begin{array}{l}\text { McDonald et } \\
\text { al.(1996) }\end{array}$ \\
\hline $\begin{array}{l}\text { Nil tilapiası (Oreochromis } \\
\text { niloticus) için biyoenerjitik } \\
\text { büyüme modeli }\end{array}$ & $\begin{array}{l}\text { Gübrelenmiş havuzlardaki sınırlayıcı besin elementleri ile balık ürününe dayanan ve } \\
\text { gübre kullanımının optimizasyonu için yarayışlı bir modeldir. }\end{array}$ & Yi (1998) \\
\hline $\begin{array}{l}\text { AWATS (Aquaculture Waste } \\
\text { Transport Simulator) }\end{array}$ & $\begin{array}{l}\text { Kafeslerde finfish balıkları yetiştiriciliğinden kaynaklanan atıkların taşınmasını } \\
\text { simule eden ve geçerliği kanıtlanmış model serileri kullanılarak geliştirilmiş atık } \\
\text { transport modelidir. }\end{array}$ & $\begin{array}{l}\text { Dudley et al. } \\
\quad(2000)\end{array}$ \\
\hline $\begin{array}{l}\text { SWAT (Soil and Water } \\
\text { Assessment Tool) }\end{array}$ & $\begin{array}{l}\text { Karasal kökenli faaliyetler sonucu su kaynaklarına olan besin elementi yüklemesinin } \\
\text { tahminine dayanan, salmon yetiştiriciliğinin yapıldığı lokal havza alanlarına ilişkin } \\
\text { uzun-dönemli su kalitesi/yeraltı suyu modellemesidir. }\end{array}$ & $\begin{array}{l}\text { Spruill et al. } \\
\quad(2000)\end{array}$ \\
\hline DEPOMOD & $\begin{array}{l}\text { Atık dağılım modeli (Atlantik salmonu ve su ürünleri yetiştiriciliği işletmeleri için } \\
\text { geliştirilmiş, kıyısal alanlarda ilk kurulum aşamasındaki balık işletmelerinde } \\
\text { maksimum üretim biyomasını tahmin etmeye uygun, bilgisayar paket programıdır) }\end{array}$ & $\begin{array}{l}\text { Cromey et al. } \\
\quad(2002)\end{array}$ \\
\hline COD-MOD & $\begin{array}{l}\text { Atık dağılım modeli (Deniz kafeslerinde yetiştirilen Atlantik mezgit balıkları için } \\
\text { DEPOMOD Modeli' nden türetilmiş, salmonidler için kullanılan modellere göre } \\
\text { daha fazla veri girdisi gerektiren bilgisayar paket programıdır) }\end{array}$ & $\begin{array}{c}\text { Cromey et al. } \\
\text { (2002) }\end{array}$ \\
\hline $\begin{array}{l}\text { IAAS (Integrated } \\
\text { Aquaculture) }\end{array}$ & $\begin{array}{l}\text { Sistemdeki balık ve ilk ürün üretimi, organik madde, fitoplankton, çözünmüş oksijen } \\
\text { ve azot dinamiklerini simule eden, STELLA paket programının kullanıldığ } 1 \text { bir } \\
\text { modeldir. }\end{array}$ & $\begin{array}{l}\text { Jamu et al. } \\
\text { (2002) }\end{array}$ \\
\hline MOM Modeli & $\begin{array}{l}\text { Norveç, Endonezya, Vietnam gibi ülkelerde uygulanmış ve kafeslerde yetiştiriciliğin } \\
\text { çevresel etkilerini esas alan bir modeldir. }\end{array}$ & $\begin{array}{l}\text { Stigebrandt et } \\
\text { al. (2004) }\end{array}$ \\
\hline Tookwinas Modeli & $\begin{array}{l}\text { Model, Thailand' da denizlerde kafeslerde levrek-Lates calcarifer ve hani balıklar1- - } \\
\text { Epinephelus spp. için oksijen bütçesini esas almaktadır. }\end{array}$ & $\begin{array}{l}\text { Tookwinas et } \\
\text { al. }(2004)\end{array}$ \\
\hline $\begin{array}{l}\text { TFST (Tilapia Farm } \\
\text { Support Tool) }\end{array}$ & $\begin{array}{l}\text { lerini dikkate alarak optimal Tilapia yetiştiricilik } \\
\text { deldir. }\end{array}$ & $\begin{array}{l}\text { De Graaf et } \\
\text { al. }(2005)\end{array}$ \\
\hline EcoWin2000 & mler gibi akvatik ekosistemlerin modellenmesine ilişkin ekosistem & $\begin{array}{c}\text { Ferreira et al. } \\
(2007 \mathrm{a})\end{array}$ \\
\hline $\begin{array}{l}\text { FARM (Farm Aquaculture } \\
\text { Resources Management) }\end{array}$ & $\begin{array}{l}\text { Kabuklu su ürünü yetiştiriciliğine ilişkin kaynak yönetimine dayanan ve STELLA } \\
\text { paket programının kullanıldığı bir modeldir. Sürdürülebilir taşıma kapasitesi için } \\
\text { maksimum kabuklu su ürünü yoğunluğunu belirlemek için geliştirilmiş ve finfish, } \\
\text { kabuklu su ürünlerine yönelik büyüme modellleri, üretim modelleri, ekonomik } \\
\text { modeller ve besin-ötrofikasyon modelleri gibi birden fazla sayıda modeli } \\
\text { kapsamaktadır. }\end{array}$ & $\begin{array}{l}\text { Ferreira et al. } \\
\quad(2007 \mathrm{~b})\end{array}$ \\
\hline KK3D N & $\begin{array}{l}\text { Denizlerde yetiştiricilikte atıkların birikimine dayanan ve yem tüketimi, ağ- } \\
\text { kafeslerin geometrisi, belirli bir zaman aralığında emisyonlardaki çeşitlilik, fekal } \\
\text { pelet çözünürlüğ̈̈, akıntı hızı, fekal peletlerin çökme hızı ve gerçek batimetrik } \\
\text { datalara ilişkin verilerin kullanıldığı bir modeldir. }\end{array}$ & $\begin{array}{l}\text { Jusup \& } \\
\text { Legovic } \\
(2007)\end{array}$ \\
\hline $\begin{array}{l}\text { PWAP (Pond - Water } \\
\text { Availability Period) }\end{array}$ & $\begin{array}{l}\text { En geçerli iklimsel ve hidrolojik koşullara dayanan balık havuzlarının su bütçesinin } \\
\text { tahminine yönelik bir modeldir. }\end{array}$ & $\begin{array}{c}\text { Kam \& Hoanh } \\
(2008)\end{array}$ \\
\hline Legovic Modeli & $\begin{array}{l}\text { Filipinler'de tatlı su, deniz, acı sularda havuz ve kafeslerde milkfish, tilapia } \\
\text { yetiştiriciliğinde besin elementi seviyesine dayanmaktadır. }\end{array}$ & $\begin{array}{c}\text { Legovic et al. } \\
(2008)\end{array}$ \\
\hline \begin{tabular}{|c|} 
RDSS (Raceway design and \\
simulation system)
\end{tabular} & $\begin{array}{l}\text { Kullanılan bilgisayar programı ile üreticilerin yetiştiricilik yaptıkları kanalları etkin } \\
\text { bir şekilde yönetmelerine olanak sağlayan bir modeldir. }\end{array}$ & $\begin{array}{l}\text { Wang et al. } \\
\text { (2008) }\end{array}$ \\
\hline CADS_TOOL & $\begin{array}{l}\text { Güneydoğu Asya'da kullanılan uygun alan seçimi, taşıma yoğunluğu, taşıma } \\
\text { kapasitesi ve ekonomik değerlendirme gibi oluşan } 5 \text { ayrı modülden oluşan bir } \\
\text { modeldir }\end{array}$ & $\begin{array}{l}\text { Halide et al. } \\
\quad(2009)\end{array}$ \\
\hline $\begin{array}{l}\text { MMFA (Mathematical } \\
\text { Material Flow Analysis) }\end{array}$ & $\begin{array}{l}\text { Tarımsal faaliyetler ile su ürünleri yetiştiriciliği faaliyetlerinden kaynaklanan azot ve } \\
\text { fosfor gibi besin elementlerini baz alarak nehirin besin elementi yüklemesini ve } \\
\text { taşıma kapasitesini belirlemek için kullanılan modeldir. }\end{array}$ & $\begin{array}{l}\text { Schaffer } \text { et al. } \\
\text { (2009) }\end{array}$ \\
\hline MERAMOD & $\begin{array}{l}\text { Atık dağılım modeli olup Akdeniz'de çipura balıkları için DEPOMOD Modeli’nden } \\
\text { adapte edilmiştir. Bu amaçla, makrobentik indikatör türler için önemli toplam katılar } \\
\text { ve diğer partiküler maddeleri ve kafes etrafındaki doğal balıklar tarafından bırakılan } \\
\text { atıkların tüketimi ile etkilerine ilişkin tahminleri dikkate alan BorlandDelphi } 7 \\
\text { bilgisayar paket programı kullanılmaktadır. }\end{array}$ & $\begin{array}{l}\text { Cromey et al. } \\
\quad(2012)\end{array}$ \\
\hline TROPOMOD & $\begin{array}{l}\text { Filipinler'de deniz ve tatlısularda kafeslerde milkfish, tilapia yetiştiriciliğinde } \\
\text { organik materyal birikimine dayanmaktadır. }\end{array}$ & \begin{tabular}{|l} 
PHILMINAQ \\
2014
\end{tabular} \\
\hline
\end{tabular}




\section{c) Yetiştiriciliğin çevresel etkilerine ilişkin modeller}

Alıcı ortamların aşırı kullanımını önlemek ve kıyısal kaynakların da kullanımını optimize etmek için modelleme ve izleme programları ile çevresel kalite standartlarının bir arada bulunduğu sistemlere ihtiyaç bulunmaktadır. Çevresel modellerden olan ve Norveç'te denizlerde kafeslerdeki yetiştiricilik faaliyetlerinde yaygın olarak kullanılan MOM sisteminin (Modelling-OngrowingFishFarmsMonitoring) izleme ve modelleme olmak üzere iki ana bileşeni bulunmaktadır (Stigebrandt et al. 2004; Halide et al. 2009) (Çizelge 5).

Çizelge 5. MOM (Modelling-OngrowingFishFarms-Monitoring) yönteminin içeriği hakkında genel bilgi (Ervik et al. 1997)

\begin{tabular}{|c|l|}
\hline \multicolumn{1}{|c|}{ Model } & $\begin{array}{l}\text { İşletmeden kaynaklı atıkların çevreye olan etkilerinin matematiksel bir } \\
\text { ifadesidir. }\end{array}$ \\
\hline İzleme programı & $\begin{array}{l}\text { İşletmenin çevreye olan etkilerinin belirlenmesi için yapılan rutin } \\
\text { ölçümlerdir. Farklı inceleme tipleri içermektedir. }\end{array}$ \\
\hline $\begin{array}{c}\text { Çevresel kalite } \\
\text { standartları }\end{array}$ & $\begin{array}{l}\text { İzleme programı ve modelin içerdiği değişkenler için sınır değerlere } \\
\text { ilişkindir. Bu sınır değerler aşıldığı takdirde taşıma kapasitesi de aşılmış } \\
\text { demektir. }\end{array}$ \\
\hline Kullanım derecesi & $\begin{array}{l}\text { Bölgenin taşıma kapasitesi ile işletmenin çevreye olan etkisi arasındaki } \\
\text { ilişkidir. Taşıma kapasitesi aşıldığı takdirde bölge aşırı kullanıma maruz } \\
\text { kalıyor demektir. }\end{array}$ \\
\hline İzlemenin seviyesi & $\begin{array}{l}\text { İzleme programının performansı hakkında bilgi verir. Her derece } \\
\text { kullanım için farklı bir izleme seviyesi bulunur. }\end{array}$ \\
\hline
\end{tabular}

Alıcı ortamlarda balık işletmelerinden olabilecek çevresel etkilere yönelik matematiksel modeller simülasyonla gösterilmekte ve sedimentte işletme kaynaklı organik maddelerin birikimi ve yayılımı ile bentik fauna üzerine etkisini tahmin etmeye odaklanmaktadır. Bazı modeller ise balık yetiştiriciliğ yapılan koy ve körfezlerde işletme kaynaklı organik maddelerin yaratacağ 1 ötrofikasyonun etkilerini tahmin etmek üzere geliştirilmiştir.

Çevresel modellerden geniş çapta kullanılan MOM (Modelling-OngrowingFishFarms-Monitoring) sistemi, balık işletmelerinin çevreye verdiği zararın bölgesel ve yerel olarak ölçeklendirilmesini yapmakta ve 4 alt modelden oluşmaktadır. Sözkonusu alt modeller, ürettikleri bilgilerle birbirlerine bağlıdır; yani bir alt modelin çıktısı diğer bir alt modelin girdisi olarak kullanılabilmektedir. Modüler bu sistemin avantajı, edinilen yeni bilgilerle yeni yönetim bilgilerinin devreye sokulabilmesi veya yeni balık türlerinin kullanılması durumunda, alt modellerin ayrılıp tek tek kullanılabilmesidir:

Balık alt modeli: İşletmelerden gelen çözünmüş askıda katı maddenin tahminine dayanmakta olup; beslenme oranı, yemin içeriği, alım şekli, birikimi ve boşaltımı bilgileri ışığında sıcaklığa ve balığın büyüklüğüne ilişkin bir modelin baz alınarak geliştirilmiş halidir.

Yayılım alt modeli: Zamana bağlı olarak akışın yönü ve hızındaki değişikliklere göre kafeslerden kaynaklanan organik atıkların tahminine dayanmaktadır. Yayılım, akış hızındaki değişiklik ve organik katı maddelerin batma hızına bağlı olarak artış ya da azalış göstermektedir.

Bentik alt modeli: İşletme kaynaklı organik madde atık düzeyi, sediment üstü sudaki oksijen miktarını kritik seviyeye getirmeyecek düzeyde olması gerekmektedir. Bu modelle, kafes işletmelerinin bulunduğu alanda akış hızının sedimentte gerekli olan oksijen geçişini sağlayarak, faunanın varlığını sürdürmesine izin verecek seviyede tutulması amaçlanmaktadır. Zira sedimentteki faunanın varlığını sürdürebilmesi için sediment üstü sudaki oksijen konsantrasyonu daima yüksek olmalıdır; aşırı indirgenmiş sedimentte oluşan kabarcıklar, tabandan kafeslere bakteri ya da hidrojen sülfür taşıyarak yetiştiriciliği yapılacak balıkları negatif etkileyebilmektedir.

Su kalitesi alt modeli: Model, minimum havalandırma oranıyla oksijen seviyesinin kritik seviyenin üzerinde tutularak ve/veya amonyum seviyesinin kritik olmayan seviyesi esas alınarak maksimum balık üretimi hesaplanmasına dayanmaktadır.

İzleme programları, MOM sisteminde olduğu gibi denizlerde kurulu kafes işletmelerinin lokal çevresel etkilerini belirlemek amacıyla kullanılmakta ve içsularda da benzer prensiplerin uygulanabileceği 
bildirilmektedir (Ervik et al. 1997; Hansen et al. 2001). İçsularda yetiştiricilik faaliyetlerinin izlenmesinde ve kafes alanının çevresel durumunun ortaya konmasında sedimente ilişkin çevresel kalite parametreleri ön plana çıkmakta ve bu kapsamda sedimentte makroomurgasız varlı̆̆ı, sedimentin bazı kimyasal analizleri $(\mathrm{pH}$, redoks potansiyeli) ile gaz, renk, koku gibi duyusal parametreler dikkate alınmaktadır (Pulatsü \& Kaya 2016b).

\section{Sonuç}

Türkiye'de "Denizlerde Balık Çiftliklerinin Kurulamayacağı Hassas Alan Niteliğindeki Kapalı Koy ve Körfez Alanlarının Belirlenmesine İlişkin Tebliğ” (RG 2007) ile denizel ekosistemlerde su ürünleri yetiştiriciliği-çevre etkileşimi konusunda ilk adımlar atılmıştır. Bu kapsamda değerlendirilen tesislerin yetiştiricilik faaliyetleri ise "Denizlerde Kurulan Balık Yetiştiriciliği Tesislerinin İzlenmesine İliş̧kin Tebliğ” (RG 2009) çerçevesinde izlenmektedir. İzlemeye alınan parametreler su kolonunda pH, askıda katı madde, Secchi Diski derinliği, tuzluluk, sıcaklık, çözünmüş oksijen, amonyum-azotu, toplam azot, toplam fosfor, klorofil-a, toplam organik karbon dip çökeltisinde yalnız toplam organik karbondur. Ayrıca işletmeler, dip çökeltisi analizleri ile ilgili tebliğin Madde 6 ikinci fikrasında belirtilen bentik flora ve fauna türleri ile birlikte Beggiatoa bakterilerinin dağllımına ilişkin tespitleri, yetiştiricilik alanında ve referans noktasında yapmakla yükümlüdürler.

Kapalı koy ve körfezlerde yapılan yetiştiricilikte taşıma kapasitesinin belirlenmesi ve bu kapasitenin aşılarak kirlilik seviyesinin artmaması açısından, belirlenen stok yoğunluğuna uyulması büyük önem arz etmektedir. Çınar et al. (2015) tarafindan bentik kommunite yapıları üzerine organik zenginleşmenin etkilerini belirlemek amacıyla yeni bir biyotik indeks olan TUBI (Türk Bentik İndeks) geliştirilmiş ve Türkiye'de denizel ekosistemler için izleme çalışmalarında, bölgeye özgü firsatçı türlerin nispi bolluğun \% 30'un üzerinde çıkması durumunda, TUBI'ye göre değerlendirme yapılması gereği bildirilmiştir.

"Durgun Yerüstü Kara İç Sularının Ötrofikasyona Karşı Korunmasına İlişkin Tebliğ" (RG 2014) ise balık yetiştiriciliği tesislerinin kurulumunda göl ve baraj göllerinin besin seviyelerinin esas alınmasını öngörmektedir. Sözkonusu tebliğ kapsamında içsularda faaliyet gösteren balık işletmelerinde su sütununda toplam fosfor, toplam azot, klorofil-a gibi parametreler (nisan ve ekim aylarında) izlenmektedir.

Sürdürülebilir su ürünleri yetiştiriciliği, sosyo-ekonomik ve ekolojik unsurlar arasındaki etkileşimlerin gözönüne alınmasını gerektirmekte; model uygulamaları, bu etkileşimlerin daha iyi anlaşılabilmesinde ve yetiştiriciliğin yönetiminde yardımcı olabilecek bir yaklaşım olarak ele alınmaktadır. Türkiye'de sürdürülebilir su ürünleri yetiştiriciliğinin bir boyutunun da kısa zamanda güvenilir sonuç verebilecek ve aynı zamanda teknolojik yaklaşımları içeren ülkemiz yetiştiricilik sistemlerine ve ortamlarına özgü model geliştirme ve uygulamaları olduğu düşünülmektedir. Bu yaklaşım ise, yetiştiriciliği minimal ekolojik değişimlerle sürdürebilmek için taşıma kapasitesi tahminlerinde bulunmak, yetiştiricilik esnasında su-sediment-biyotaya ilişkin çevresel kalite standartlarını esas almak ve çevresel değişimleri izlemede ilgili yasal düzenlemelere uyum göstermek gibi temel prensipler ışı̆̆ında olası gözükmektedir.

\section{Kaynaklar}

Alvarado, J.L. (1997). Feeding Tomorrow's Fish: Aquafeeds and the Environment. Cahiers Options Mediterraneennes, Vol: 22, CIHEAM, $307 \mathrm{p}$

Anyadike, C. C., Mbajiorgu, C. C., \& Ajah, G.N. (2016). Review of aquacultural production system models. Nigerian Journal of Technology, 35 (2), 448-457

Aşır, U. \& Pulatsü, S. (2008). Estimation of the nitrogen - phosphorus load due to cage cultured rainbow trout (Oncorhynchus mykiss Walbaum, 1792) in Kesikköprü Dam Lake: Comparison of pelleted and extruded feed. Turkish Journal of Veterinary and Animal Sciences, 32, 417-422

Aytekin, B. (2007). Karakaya Baraj Gölü'nün Kafeslerde Gökkuşağı Alabalık (Oncorhynchus mykiss Walbaum, 1792) Külttürü için Taşıma Kapasitesinin Belirlenmesi. Yüksek lisans tezi, Gaziosmanpaşa Üniversitesi Fen Bilimleri Enstitüsü, Tokat

Bueno, G.W., Bureau, D., Skipper-Horton, J.O., Roubach, R., Mattos, F.T., \& Bernal, F.E.M. (2017). Mathematical modelling for the management of the carrying capacity of aquaculture enterprises in lakes and reservoirs. Pesq. Agropec. Bras. Brasilia, 52 (9), 695-706 
BSGM. (2018). T.C. Gıda Tarım ve Hayvancılık Bakanlığı, Balıkçılık ve Su Ürünleri Genel Müdürlüğ̈ü. $\mathrm{Su}$ Ürünleri İstatistikleri. [Online] Available: http://tarimorman.gov.tr/sgb/Belgeler/SagMenuVeriler/ BSGM.pdf. (02.12.2018)

Buhan, E., Koçer, M.A., Polat, F., Doğan, H. M., Dirim, S., \& Neary, E. (2010). Almus Baraj Gölü su kalitesinin alabalık yetiştiriciliği açısından değerlendirilmesi ve taşıma kapasitesinin tahmini. Gaziosmanpaşa Üniversitesi Ziraat Fakültesi Dergisi, 27 (1), 57-65

Bulut, C., \& Akçimen, U. (2015). Karanfilliçay Deresi gökkuşağı alabalığı (Oncorhynchus mykiss Walbaum, 1792) yetiştiriciliğinden kaynaklanan azot-fosfor yükünün tahmini. II. Balıklandırma ve Rezervuar Yönetimi Sempozyumu. 20-22 Mayıs, Eğirdir. s. 235

Bureau, D.P., \& Hua, K. (2010). Towards effective nutritional management of waste outputs in aquaculture, with particular reference to salmonid aquaculture operations. Aquaculture Research, $41,777-792$

Büyükcapar, H.M. \& Alp, A. (2006). The carrying capacity and suitability of the Menzelet Reservoir (Kahramanmaraş-Turkey) for trout culture in terms of water quality. Journal of Applied Sciences, 6 (13), 2774-2778

Canale, R.P., Whelan, G. Switzer, A., \& Eisch, E. (2016). A bioenergetic approach to manage production and control phosphorus discharges from a salmonid hatchery. Aquaculture, 451, 137146

Cho, C.Y., (1992). Feeding systems for rainbow trout and other salmonids with reference to current estimates of energy and protein requirements. Aquaculture, 100, 107-123

Cromey, C.J., Nickell, T.D., \& Black, K.D. (2002). DEPOMOD - modelling the deposition and biological effects of waste solids from marine cage farms. Aquaculture, 214, 211- 239

Cromey, C.J., Thetmeyer, H., Lampadariou, N., Black, K.D., Kögeler, J., \& Karakassis, I. (2012). MERAMOD - predicting the deposition and benthic impact of aquaculture in the eastern Mediterranean Sea. Aquaculture Environment Interactions, 2, 157-176

Culberson, S.T., \& Piedrahita, R.H. (1996). Aquaculture pond ecosystem modelling: temperature and dissolved oxygen prediction - mechanism and application. Ecological Modelling, 89, 231-258

Çevlik, H., \& Elibol, M. (2009). Yamula Baraj Gölü limnolojisi. T. C. Çevre ve Orman Bakanlığı Devlet Su İşleri Genel Müdürlüğü, 186 s., Ankara.

Çevlik, H. (2013). Ermenek Baraj Gölü limnolojisi. T. C. Çevre ve Orman Bakanlığı Devlet Su İşleri Genel Müdürlüğü, 251 s., Ankara.

Çınar, M. E., Bakır, K., Öztürk, B., Katağan, T., Dağlı, E., Açık, Ş. Doğan, A., \& Bakır, B. B. (2015). TUBI (Turkish Benthic Index): A new biotic index for assessing impacts of organic pollution on benthic communities. Journal of Black Sea/Mediterranean Environment, 21(2), 135-168.

ÇSB. (2019). Çevresel açıdan sürdürülebilir çevre dostu balık çiftlikleri sisteminin oluşturulması k1lavuzu. [Online] Available: http://www. webdosya.csb.gov.tr/csb/dokumanlar/cygm0030.pdf. (10.01. 2019)

De Graaf, G. J.,Johan, P. J. \& Verreth, A. J. (2005). Simulation of Nile tilapia (Orechromis niloticus L.) culture in ponds, through individual based modeling, using a population dynamic approach. Aquaculture Research, 36 (5), 455-471 
Demir, T., Koçer, M.A., Örnekçi, G.N., Uslu, A.A., Birici, N., Gürçay, S., Şeker, T., Özbey, N., Arısoy, G., \& Özmen, H. (2015). Fosfor bütçe modeliyle Çat Baraj Gölü'nün (Adıyaman) kafeslerde alabalık yetiştiriciliği için taşıma kapasitesinin ampirik tahmini. II. Balıklandırma ve Rezervuar Yönetimi Sempozyumu. 20-22 Mayıs, Eğirdir, s.119

Dillon, P.J., \& Rigler, F.H. (1974). A test of a simple nutrient budget model predicting the phosphorus concentration in lake water. J. Fish. Res. Board Can., 31, 1771-1778

Dominguez, L.M., Calaro, G.L., Martin, J.M.V., Robaina, L.R. \& Fernandez-Palacios, H. (1997). Retention and discharge of nutrients from a cage farm in the Canary Islands. Preliminary results. Cahiers Options Mediterraneennes Vol: 22, CIHEAM, $307 \mathrm{p}$

Dudley, R.W., Panchang, V.G., \& Newell, C.R. (2000). Application of a comprehensive modelling strategy for the management of net-pen aquaculture waste transport. Aquaculture, 187, 319-349

Ervik, A., Hansen, P.K., Aure, J., Stigebrandt, A., Johannessen, P., \& Jahnsen, T. (1997). Regulating the local environment impact of intensive marine fish farming I. The concept of the MOM System (Modelling-Ongrowingfishfarms- Monitoring). Aquaculture, 158, 85-94

Ferreira, J.G., Sequeira, A., Hawkins, A.J.S., A. Newton., \& R. Pastres, R. (2007a). Assessment of production and water quality impacts of shellfish aquaculture using farm-scale models. Available: http://www.farmscale.org/resources/FARM\%20AND\%20E2K.pdf (25.04.2008)

Ferreira, J.G., Hawkins, A.J.S. \& Bricker, S.B. (2007b). Management of productivity, environmental effects and profitability of shellfish aquaculture - the Farm Aquaculture Resource Management (FARM) model. Aquaculture, 264, 160-174

GESAMP. 1991. Coastal Modelling. Reports and Studies. No:43, 189 p., International Atomic Energy Agency, Vienna

Halide, H., Stigebrandt, A., Rehbein, M. \& McKinnon, A.D. (2009). Developing a decision support system for sustainable cage aquaculture. Environmental Modelling\&Software, 24, 694-702

Hansen, P.K., Ervik, A., Schaanning, M., Johannessen, P., Aure, J., Jahnsen, T. \& Stigebrandt, A. (2001). Regulating the local environment impact of intensive marine fish farming II. The monitoring programme of the MOM System (Modelling-Ongrowingfishfarms- Monitoring). Aquaculture, 194, 75-92

Jamu, D.M. \& Piedrahita, R.H. (2002). An organic matter and nitrogen dynamics model for the ecological analysis of integrated aquaculture/agriculture systems: I. Model development and calibration. Environmental Modelling, 17, 571-582

Jusup, G., \& Legovic, T. (2007). Impact of aquacultures on the marine ecosystem: Modelling benthic carbon loading over variable depth. Ecological Modelling, 200, 459-466

Kam, S.P. \& Hoanh, C.T. (2008). Modelling Pond-Water Availability for fish culture. [Online] Available:

http://www.mssanz.org.au/MODSIM07/papers/23_s31/ModellingPond_s31_Kam_.pdf $(25.04 .2010)$

Kaya, D., \& Pulatsü, S. (2017). Sediment-focused environmental impact of rainbow trout (Oncorhynchus mykiss Walbaum, 1792) cage farms: Almus Dam Lake (Tokat). Turkish Journal of Fisheries and Aquatic Sciences, 17 (2), 345-352

Legovic, T., Palerud, R., Christensen, G.N., White, P., \& Regpala, R. (2008). Development of a model to estimate aquaculture carrying capacity in the three areas of the Philippines. Science Diliman, $20(2), 23-31$ 
McDonald, M.E., Tikkanen, C.A., Axler, R.P., Larsen, C.P. \& Host, G. (1996). Fish Simulation Culture Model (FISC). A bioenergetics based model for aquacultural waste load application. Aquacultural Engineering, 15(4), 243- 259

McKindsey, C. W.,Thetmeyer, H., Landry, T., \& Silvert, W. (2006). Review of recent carrying capacity models for bivalve culture and recommendations for research and management. Aquaculture, 261, 451-462, doi: 10.1016/j.aquaculture.2006.06.044

Mikailsoy,F.(2019).Matematiksel modelleme. [Online] Available: http://www.Matematikselmodellerin-

seçim-kriterleri-fariz-mikailsoy-f.pdf (15.01.2019)

Özdal, B., \& Pulatsü, S. (2012). Using of the computer software for the sustainable rainbow trout cage culture : A case study in Gökçekaya Dam Lake (Ankara, Turkey). Ege Journal of Fisheries an Aquatic Sciences, 29 (1), 49-54

PHILMINAQ. 2014. Modelling of aquaculture impact and carrying capacity in Philippines using TROPOMOD.[Online]Available:http://www.slideshare.net/patrickgwhite/tropomod-modellingof-sabbac-web (12.01.2014)

Polat, F., \& Özmen H. (2011). Almus Baraj Gölün'de trofik seviyenin belirlenmesi ve gölün fosfor taşıma kapasitesinin araştırılması. Ekoloji, 20 (78), 53-59

Pulatsü, S. (2003). The application of phosphorus budget model estimating the carrying capacity of Kesikköprü Dam Lake. Turkish Journal of Veterinary and Animal Sciences, 27(5), 1127-1130

Pulatsü, S., Topçu, A \& Atay, D. (2014). Su Kirlenmesi ve Kontrolü (Genişletilmiş İkinci Bask1) Ankara Üniversitesi Ziraat Fakültesi Yayın No:1617, Ders Kitabı: 569, Ankara

Pulatsü, S., \& Kaya, D. (2016a). Su ürünleri yetiştiriciliğinde balık beslemenin çevresel boyutu. Türkiye Klinikleri J Anim Nutr\&NutrDis-Special Topics, 2 (1), 33-41

Pulatsü, S., \& Kaya, D. (2016b). Kafeslerde gökkuşağı alabalığı yetiştiriciliğinde (Karaova Baraj Gölü, Kırşehir) lokal çevresel durumun ve taşıma yoğunluğunun tahmini. Ege Journal of Fisheries an Aquatic Sciences, 33 (4), 313-320

RG. 2007. Denizlerde Balık Çiftliklerinin Kurulamayacağı Hassas Alan Niteliğindeki Kapalı Koy ve Körfez Alanlarının Belirlenmesine İlişkin Tebliğ. 24 Ocak 2007 Tarih ve 26413 Sayılı Resmi Gazete

RG. 2009. Denizlerde Kurulan Balık Yetiştiriciliği Tesislerinin İzlenmesine İlişkin Tebliğ 13 Haziran 2009 Tarih ve 27257 Sayılı Resmi Gazete

RG. 2014. Durgun Yerüstü Kara İç Sularının Ötrofikasyona Karşı Korunmasına İlişkin Tebliğ. 26 Şubat 2014 Tarih ve 28925 Sayılı Resmi Gazete

Ross, L.G., Telfer, T.C., Falconer, L., Soto, D., \& Aguilar-Manjarrez, J. (2013). Carrying capacities and site selection within the ecosystem approach to aquaculture. In: Site selection and carrying capacities for inland and coastal aquaculture, FAO/ Institute of Aquaculture, University of Stirling, Expert Workshop, 6-8 December 2010, pp.19-46

Roy, A.K. (2006). Modeling in Aquaculture. In: Modelling, Forecasting, Artificial Neural Network and Expert System in Fisheries and Aqaculture-Chapter 6, 67-86

SEPA. 2014. Fish Farm Manual. Scottish Environment Protection Agency (SEPA). [Online] Available: http://www.sepa.org.uk/regulations/water/aquaculture/fish-farm-manual/ (15.01.2019) 
Schaffner, M., Bader, H.P., \& Scheidegger, R. (2009). Modelling the contribution of point sources and nonpoint sources to Thachin River water pollution. Science of the Total Environment, 407, 4902-4915

Shearer, K.D. (1995). The use of factorial modeling to determine the dietary requirements for essential elements in fishes. Aquaculture, 133 (1), 57-72

Spruill, C.A.,Workman, S.R., \& Taraba, J.L. (2000). Simulation of daily and monthly stream discharge from small watersheds using the SWAT model. American Society of Agricultural Engineers, 43, 1431-1439

Stigebrandt, A., Aure, J., Ervik, A. \& Hansen, P.K. (2004). Regulating the local environment impact of intensive marine fish farming III. A model for estimation of the holding capacity in the modelling-ongrowingfishfarms- monitoring system. Aquaculture, 234, 239-261

Tookwinas, M., Songsangjinda, P., Kajonwattanakul, S., \& Singharachai, C. (2004). Carrying capacity estimation of marine finfish cage culture in Pathew Bay, Chumphon Province, Southern Thailand. Southeast Asian Fisheries Development Center. TD/RES/91, LBCFM-PD No:34, Thailand

Verep, B., Çelikkale, M.S., Düzgüneş, E., \& Okumuş, İ. (2002). Uzungöl'ün genel hidrografik özellikleri ve taşıma kapasitesi. Türk Sucul Yaşam Dergisi, 1, 148-157

Wang, Y.-H.,Turton, R., Semmens, K. \& Borisova, T. (2008). Raceway design and simulation system (RDSS): An event-based program to simulate the day-to-day operations of multiple-tank raceways. Aquacultural Engineering, 39, 59-71

Yi, Y.1998. A bioenergetics growth model for Nile tilapia (Oreochromis niloticus) based on limiting nutrients and fish standing crop in fertilized ponds. Aquacultural Engineering, 18, 157-173 